\title{
Smart Anti-Theft Bag for Business Men Depending on the Raspberry-Pi3 Environment
}

\author{
Zainab Khyioon Abdalrdha ${ }^{1}$, Ahmed Kareem Ridha ${ }^{2}$, Ali Qasim Mohammmed ${ }^{3}$ \\ ${ }^{1}$ Teacher, ${ }^{2}$ Assistant Teacher, and ${ }^{3}$ Assistant programmer \\ ${ }^{1,2}$ Department of Computer Science, Collage of Education, University of Mustansiriyah, Iraq \\ ${ }^{3}$ Computer Center, University of Mustansiriyah, Iraq
}

\begin{abstract}
To protect people from thefts, especially businessmen who have important files are wary of losing them and in order to preserve them. The smart bag is designed to contain many features where in this paper, a smart bag against theft is designed and implemented to reveal the identity of the thief in case it is lost. The system was developed on the basis of a Raspberry board (Pi3) and passed through the following steps, in the first stage, the image of the thief was captured by simply opening the bag, while in the second stage, the captured image was sent by e-mail to the owner of the bag and, eventually, the thief would be identified through a picture obtained by e-mail and The aim of the bag design and implementation is to protect the paper information or documents of business or security personnel. The proposed system in this work provides the user with a technology to increase the level of security of information programmed in Python.
\end{abstract}

Key Words: Raspberry Pi, Arduino UNO, Hardware platforms, Ultrasonic Sensing Theory, HC-SR04 distance sensor.

\section{INTRODUCTION}

Raspberry Pi is a computer that looks like a regular computer but is smaller. It can use different types of processors, and it can be installed for many versions of the Linux operating system it is not possible to install Microsoft Windows on it. Most aspiring computer scientists consider the Raspberry Pi to be an ideal device, as it is powerful, affordable, and hard to break. It can also be used for browsing, sending an email to write a message based on the use of a word processor [1]. This small computer features high sound quality and is capable of playing 3D games in addition to great HD quality and video playback. This device can use processor (ARM) which does all the tedious operations to work. Here are some used programs which can be downloaded from the official forum which is free under the category of NOOBS (new software out of the box) RASPBIAN, PIDORA, OPENELEC, RASPBMC, RISC OS, ARCH LINUX. It also features support for the main programming language for working and marking that is Python. It also supports BASIC, C, C ++, and JAVA languages among others [2]. In this paper, we will discuss in the second part, the design Bag Smart, in the third part describing the Tools used in Design Bag Smart, and the fourth part describing the proposed system, also describes the structure \& the Execution of the proposed system.

\section{DESIGN OF "BAG SMART"}

The smart bag is designed to contain many features, including hardware design \& software design.

\section{A. HARDWARE DESIGN}

1. Raspberry type (Pi3 Model B) device, one number.

2. "Blue and yellow" LED lights (2)

3. HDMI cable number (1).

4. USB Camera web cam number (1)

5. Connect the number wires as needed.

6. The USB Ethernet cable that connects the device to the computer

7. Mouse and Keyboard 
8. Ultrasonic sensor to detect obstacles

9. RAM 16 GB

10. The battery

\section{B. Software DESIGN:}

$>\quad$ Operating system (the raspbian): Raspbian is easiest to use, best looking as it contains a set of virtualization software and is the best for Raspberry Pi's.

$>$ Python language: Python is a programming language that is very powerful and easy to learn. It has the advantage of being highly efficient data structures with a simple approach that is effective for object-oriented programming. It is considered an ideal language for scripting and is in most fields a fast developing application because it is able to build Python elegant syntax and dynamic writing, along with its interpretive nature.

\section{Tools used in Design Bag Smart:}

This section consists of part Overview of Raspberry Pi, Comparison of raspberry pi and hardware platforms, It also describes Ultrasonic Sensing Theory.

\subsection{Raspberry Pi Overview:}

The Raspberry Pi is a tablet computer that includes five Raspberry Pi models in the market i.e. (B +, A +, B and A) and module computing (a computing module development kit is currently only available as part of it) and is the size of a credit card. $\mathrm{A}$ and $\mathrm{B}$ both use the same $\mathrm{PCB}$, while $\mathrm{A}+$ and $\mathrm{B}+$ are a new design that both have the same form factor. The unit of calculation cannot be used independently and is an entirely Various factors. For this project we have adopted Rev3 B [3]. Diagram in Figure (1) a Raspberry Pi 3 The four USB ports included in the Raspberry Pi 3 have been used which provide a connection to a mouse, the keyboard, or anything else you feel we can use to connect [4].

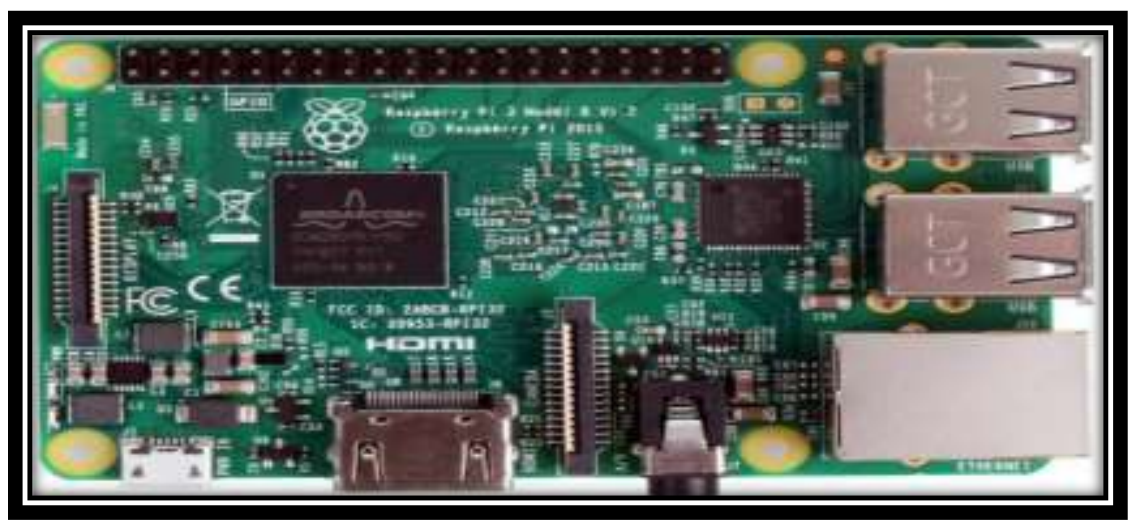

Figure 1: Raspberry Pi3[4].

\subsection{Comparison of platforms for Raspberry and others:}

Raspberry $\mathrm{Pi}$ is a computer board that is characterized by its small size, strength, in addition to being cheap and can be penetrable, and one of its most significant advantages is that it can be geared towards education and was launched in 2012 as seen in the article (Figure 2). It works the same way as a standard computer. The Raspberry Pi board shown in Figure. 2 and Figure. 3 contains several basic components that include (processor, RAM and graphics chip) in addition to other optional hardware [5]. An SD Flash memory acts as a disk drive for a Raspberry Pi processor as the unit is powered by a micro USB connector while an Ethernet / LAN cable is used to connect to the Internet [6, 7]. 


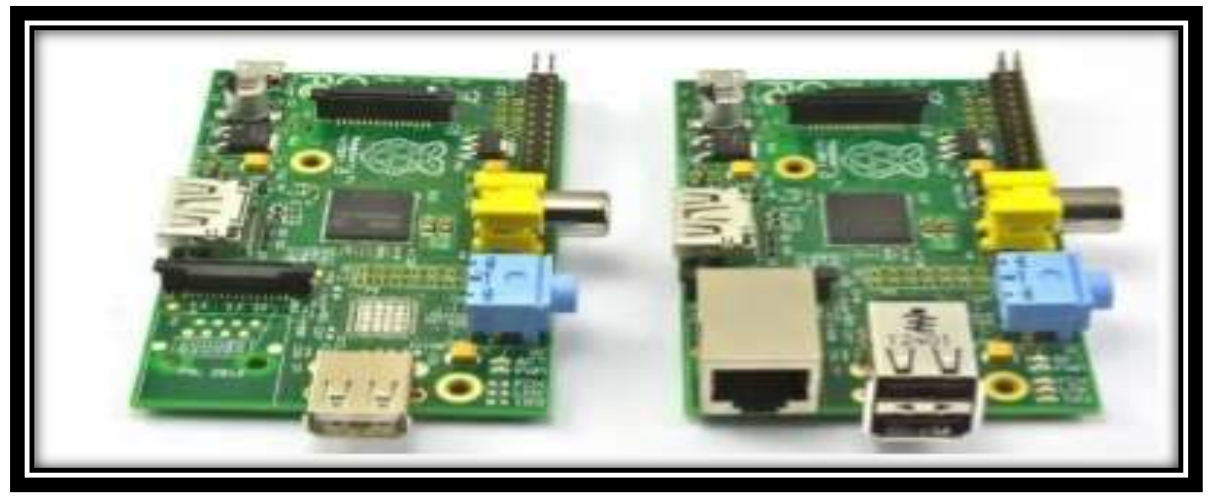

Figure 2: The raspberry Pi prototype board for both Models A and B [8]

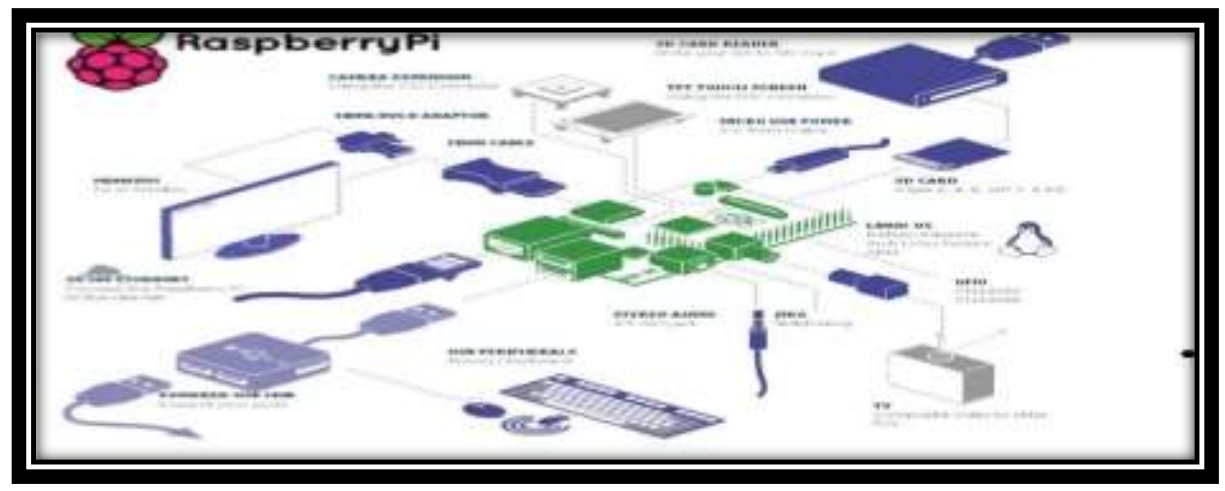

Figure 3: The basic components of a Raspberry Pi [8]

Raspberry Pi, a free and open source Linux operating system that makes it a low-priced system previously called Raspbian, which is a great match for the Raspberry Pi [6]. The performance of the Raspberry Pi will be compared against various platforms as in (Figure 4):

- Arduino - A computing platform that is characterized as open source and based on a control panel that is characterized by its accuracy and simplicity, and has an environment for writing the program for the board (Figure 4A). Lights, motors, and other actuators can be controlled as they can receive input from a variety of sensors [9].

- BeagleBone Black - This is a low-powered Texas Instruments single-board processor with an ARM Cortex-A8 core (Figure 4B). It's also a small, credit-card-sized computer that can run across an operating system. Like Linux / Android 4.0 the main difference between it and Arduino is that it can be practically converted into a small computer that can run on operating systems. The Beagle Bone is built to work and has more processing capacity than Arduino and at a much higher level [10].

Phidgets - A set of 'plug and play' building blocks dedicated to the interaction between physical and virtual worlds via USB sensing. Phidgets include USB-based hardware boards for I / O drives (Figure 4D). Its architecture allows for monitoring and control of all relevant tools and can provide an interactive interface for the end user that is visible on the screen. In addition, the system contains APIs for applications available within the library along with other toolkits, allowing programmers to use Phidgets and quickly develop interfaces without having to know design issues $[9,11]$.

- Udoo - A compact board computer that is Arduino compatible and can be used with both Linux operating systems, this board is a powerful model for software development and design. And Udoo integrates with the most popular communication ports (Ethernet, WiFi, USB, HDMI and SATA with a standard pin for rapid prototyping applications and it can be summed up that Udoo strives to bring the best elements of Raspberry Pi and Arduino together in one small computer. [12]. Table (1) will display the size, weight, and cost of the Raspberry Pie compared to the above-mentioned platforms. 
International Journal of Engineering Research And Advanced Technology, Vol.6 (12), December-2020

Table1: Compare the size, weight and cost of platforms [8]

\begin{tabular}{|l|c|c|c|}
\hline \multicolumn{1}{|c|}{ Name } & Size (mm)* & $\begin{array}{c}\text { Weight } \\
(\mathbf{g})^{*}\end{array}$ & $\begin{array}{c}\text { Cost per } \\
\text { node US\$* }\end{array}$ \\
\hline Raspberry $\mathrm{Pi}$ & $85.6 \times 53.98 \times 17$ & 45 & $\mathbf{2 5 - 3 5}$ \\
\hline Arduino (Uno) & $\mathbf{7 5 \times 5 3 \times \mathbf { 1 5 }}$ & $\sim \mathbf{3 0}$ & 30 \\
\hline BeagleBone Black & $86.3 \times 53.3$ & 39.68 & 45 \\
\hline Phidgets & $81.3 \times 53,3$ & 60 & $50-200$ \\
\hline Udoo & $110 \times 85$ & $120-170$ & $99-135$ \\
\hline
\end{tabular}

* (The smaller value is better)

The most outstanding power mode in Raspberry Pi [13]:

The run mode - All functionality of the ARM core, plus the CPU, is available.

Standby mode - In this mode, power circuits in the core remain active even when the CPU's special components that process instructions are turned off.

The Shutdown mode - no power available.

The dormant mode - All caches are running even when the kernel is turned off.

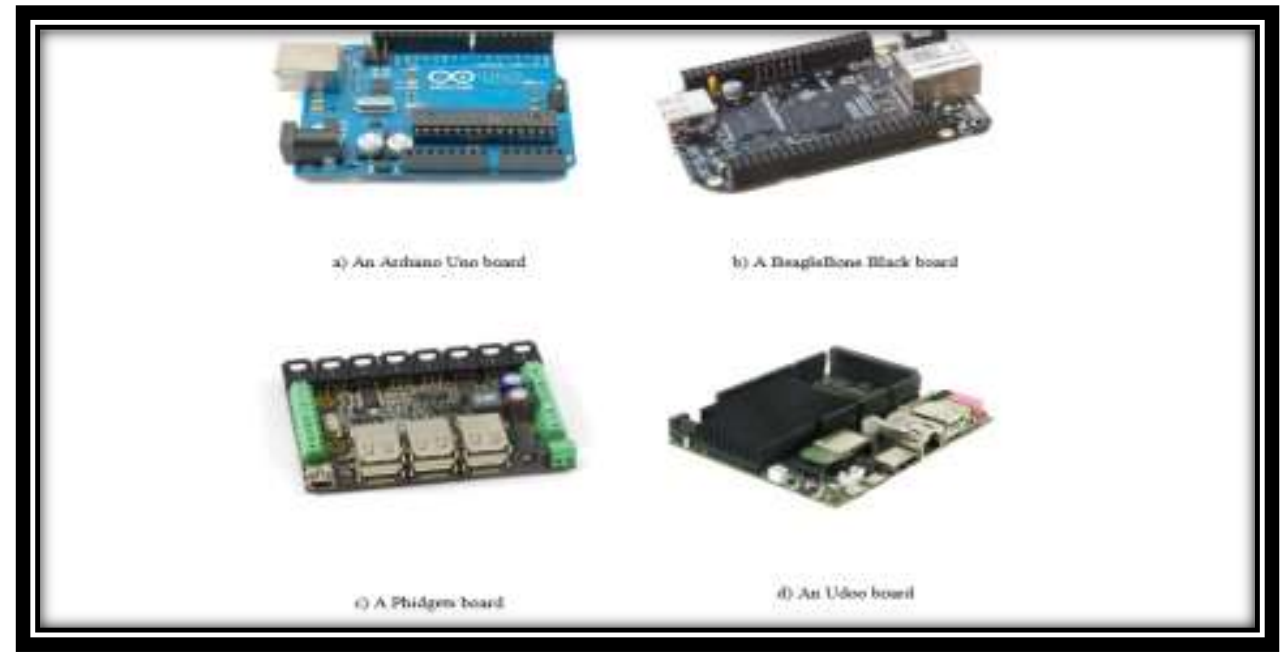

Figure 4: Various hardware platforms [8]

\subsection{Ultrasonic Sensing Theory:}

Ultrasound waves are waves that cannot be heard by humans because their wavelength is higher than 20 kilohertz. This theory is based on measuring the time of pulsed reflection as the ultrasound transducer transmits a wave pulse and receives a reflection signal called echoes as shown in Figure 5. When the pulse of the transmitted wave detects an object, the reflected wave, the echo wave, bounces back to the transducer [14]. 


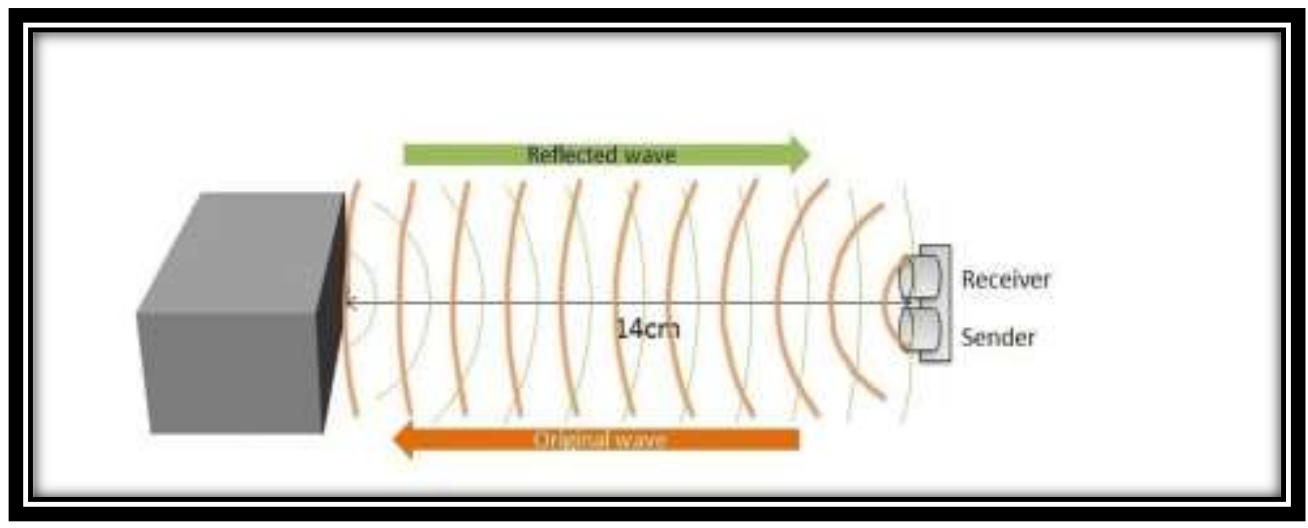

Figure 5: Ultrasound of the sensor principle [14].

The transmitter and receiver unit are used for ultrasound sensors. To carry out this experiment, a $40 \mathrm{kHz}$ ultrasound sensor was used. A high-precision microcontroller has been developed and its purpose is to test the system. The measurement of the obstacle distance can be calculated based on equation (1) [15].

According to the following formula the object distance can be calculated:

$\mathrm{f}=\mathrm{r} \times \mathrm{x} 2$

F: represents the distance of the object (m), r: the time delay between the emission of the wave and the reception of the echo (s), and $\mathrm{x}$ : the velocity of sound above the sound waves $(\mathrm{m} / \mathrm{s})$ that depends on the air temperature. Figure 6 represents the relationship between ultrasound velocity and air temperature.

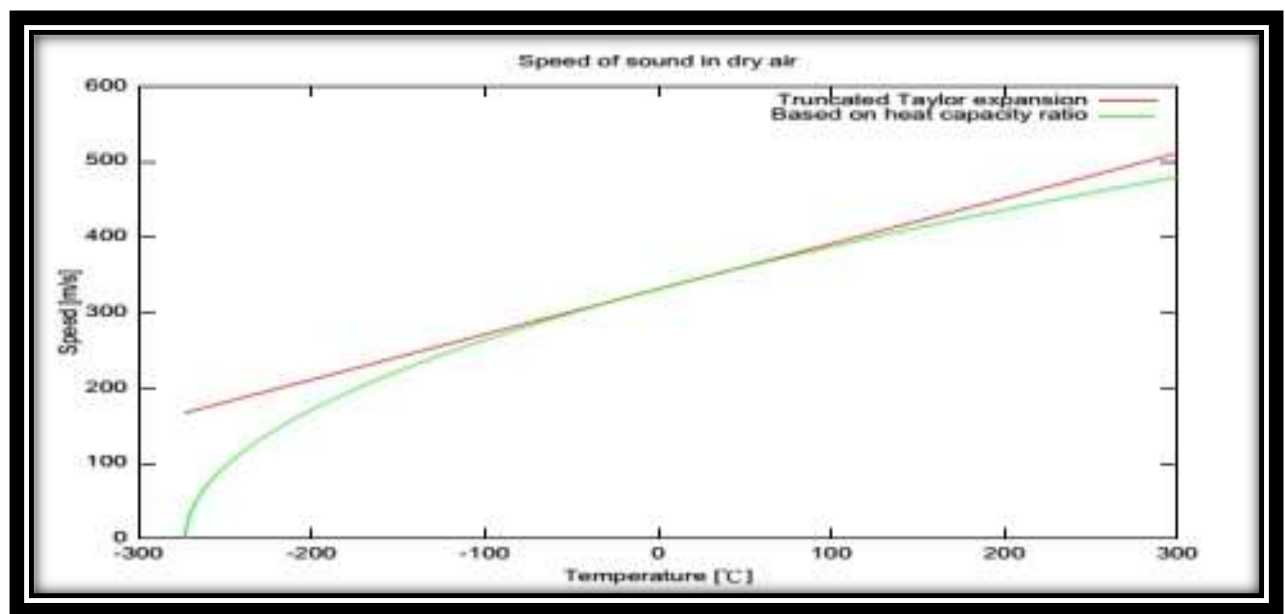

Figure 6: The relationship between speed of sound and air temperature [15]. 


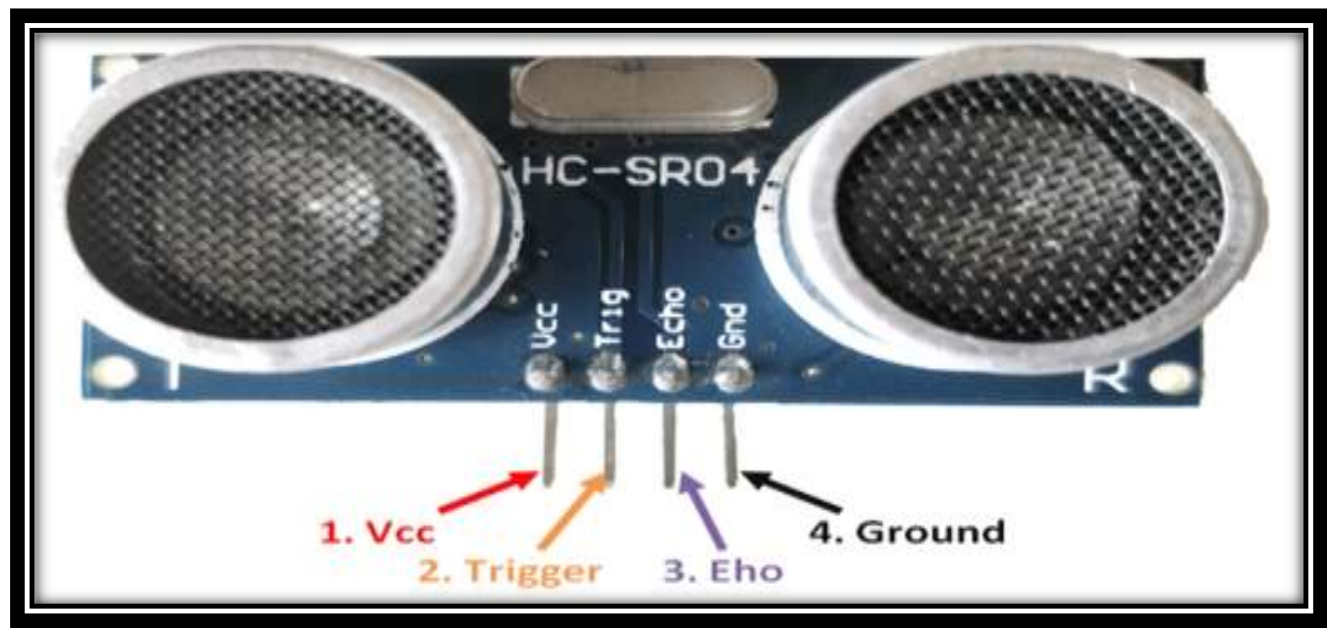

Figure 7: Ultrasound sensor HC-SR04 [16]

As is Figure 7 which shows that the HC-SR04 ultrasound sensor is a sensor that can be used in many applications that require distance measurement or sensor objects. This sensor consists of two eyes which form the ultrasound transmitter and receiver The sensor works with the formula according to which distance $=$ velocity $\mathrm{x}$ time as the ultrasound transmitter sends an ultrasound wave and when the wave travels in the air and during its transmission it is intercepted by any substance, where it is reacted Back towards the sensor, the receiving waveforms, as shown in the image below, are also distinguished by the fact that this sensor has 4 teeth, and their names are Vcc, Trigger, Echo and Ground, respectively The HC-SR04 Distance Sensor is commonly used with Arduino, ARM, PIC, Raspberry Pie, etc [16].

\section{The proposed system:}

Design and implementation of the smart bag works by a smart system designed in the Python language depending on the Raspberry pi3 where a USB web camera was used and the use of ultrasonic sensors called ultrasonic sensors The ultrasound sensors work on the principle of echo Different is very important. And used LED lights (number 2) blue and yellow color to keep pace with the development of science and technology, it was necessary to make a smart bag with high security and discover unauthorized persons or in the event of losing the bag.

\subsection{The General Structure of the Proposed System:}

This section illustrates the proposed general structure for the system. It is shown this in the flow chart (8).

Raspberry $\mathrm{Pi}$ is the main component of the project. We will use the USB webcam to take pictures. We can explain the scheme of the smart bag where first the bag will be opened and after 20 seconds the image is taken and then sent to the email and this work will continue in the transmission every minute to alert the owner of the bag that there is someone who opened the bag and this will send the image to the owner. 


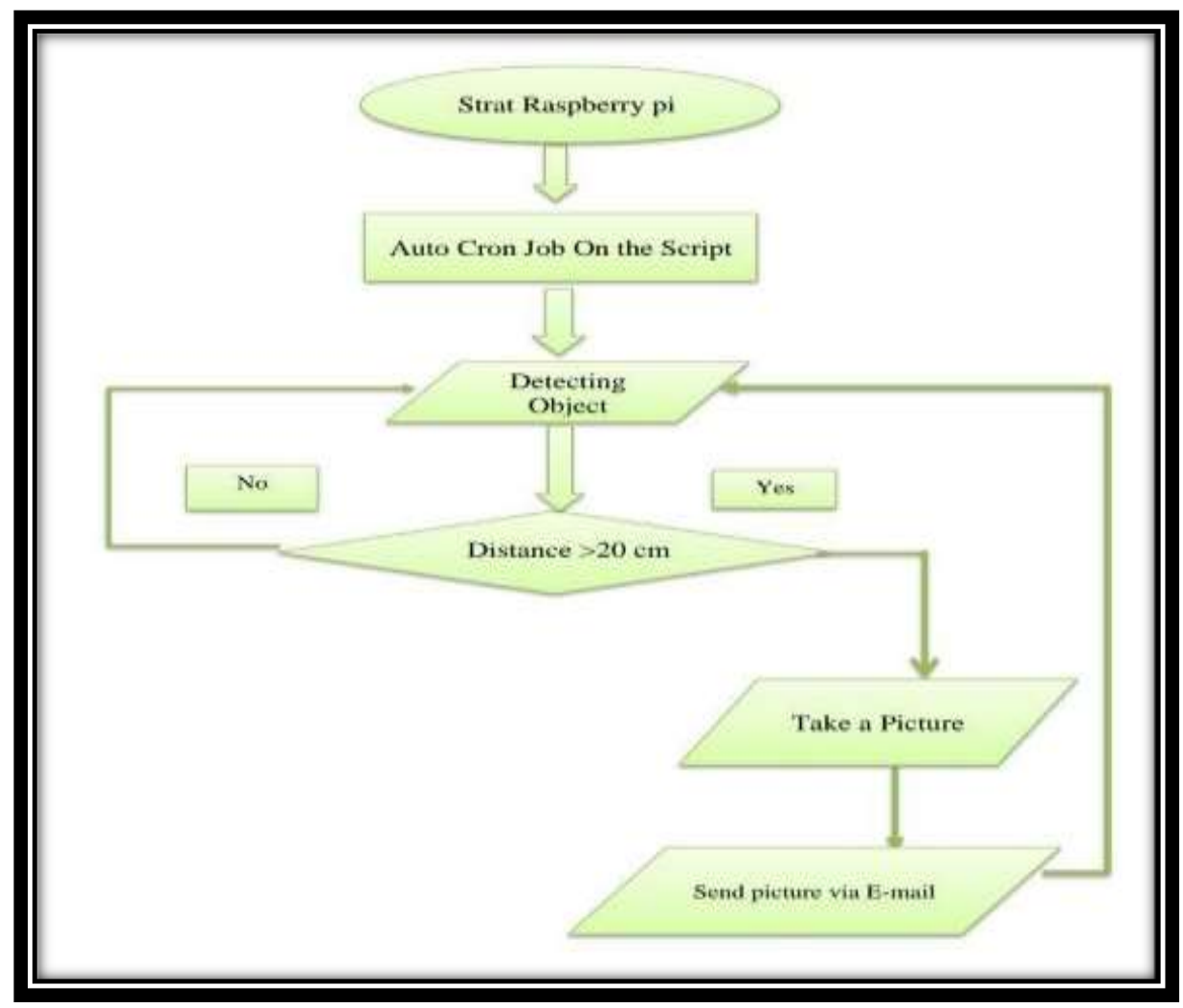

Figure (8) Flow Chart of Proposed System

\subsection{The Execution of the Proposed System:}

Camera Unit The camera unit is compatible with all Raspberry Pi models including the Raspberry Pi 1, 2 and 3. Its panel size is approximately $25 \mathrm{~mm} \times 20 \mathrm{~mm} \times 9$, Regarding still images, the camera is capable of capturing still images of $2592 \times 1944$ pixels with two LEDs, one is blue and the other is yellow. When the bag is opened, the photo is taken, the background photos of the owner are emailed to you, the blue LED is lit, the yellow LED will still wait 60 seconds to send it back. As shown in Figure (9) and Figure (10).

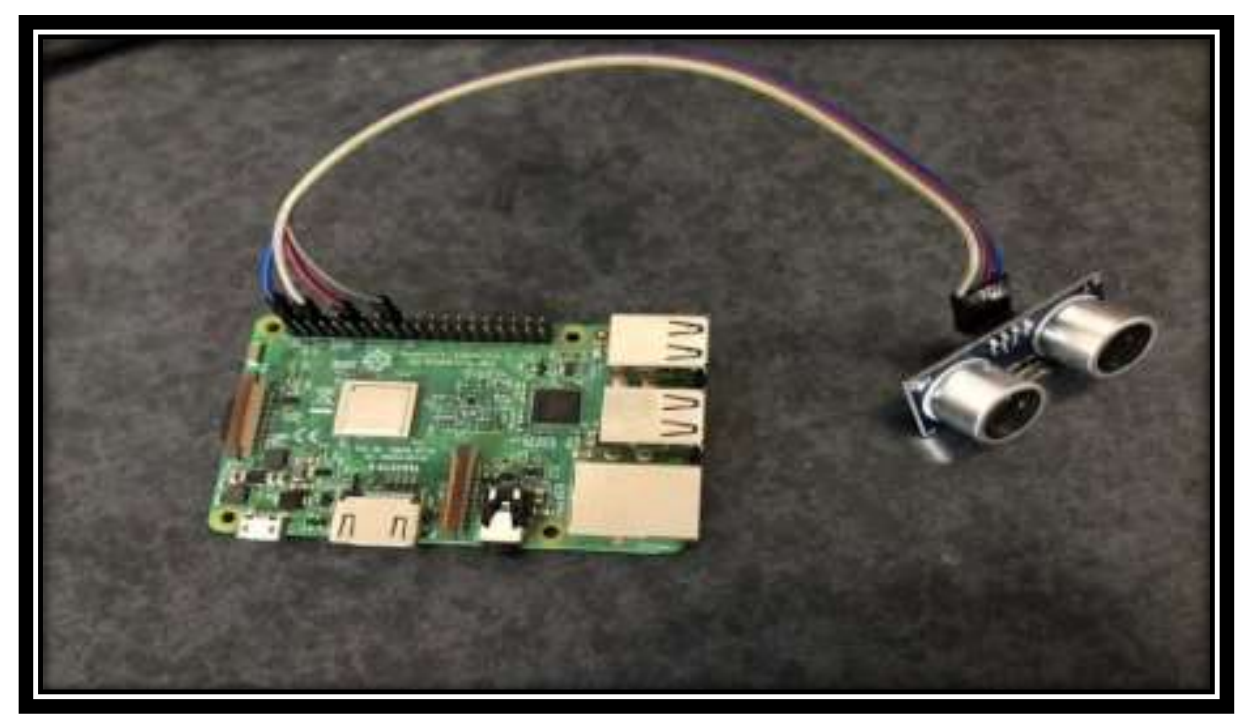

Figure (9): Distance Measurement with the Circuit

$>$ Ultrasonic sensor tested:

1. The circuit is connected to the circuit board.

2. When placing an object (fixed at a distance), where the proposed system detected the foreign body and the image was taken and sent through the amyl in the first (20) seconds and the process was repeated more than once for different bodies of different sizes. 


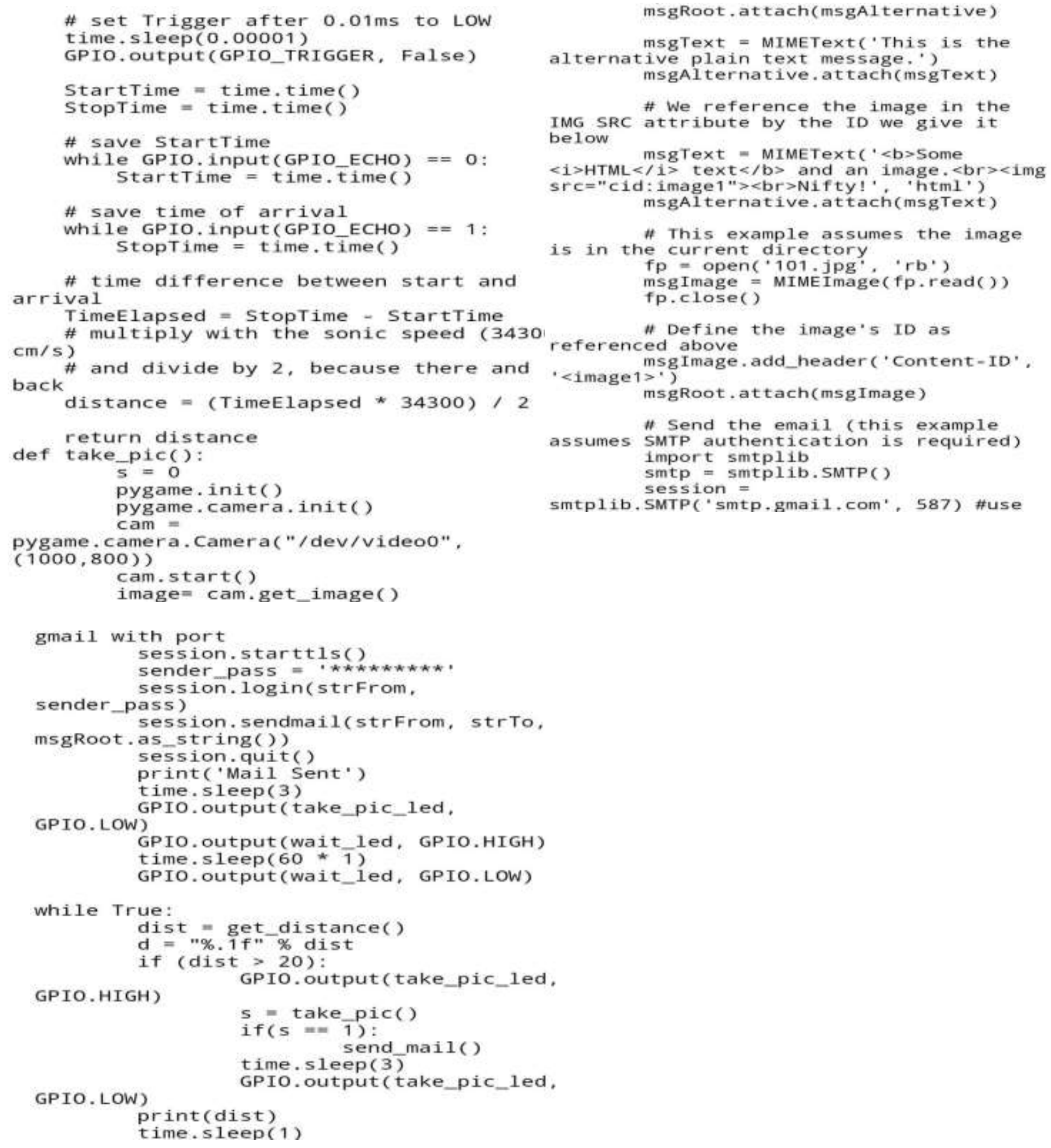

\section{CONCLUSION}

The main conclusions from designing and implementation of the proposed system are:

1. This proposed system can be used in python.

2. The main purpose of this paper-based method is to design and implement an anti-theft smart bag, and it has been fully achieved. The simulation of the smart bag app is an essential platform for the next generation of auxiliary devices to help people with important documents or needs move safely inside and out, and it is effective. It leads to good results in detecting thieves by opening the bag and within the first (20) seconds, the image is captured by the sensors and other components. This system 
provides a low-cost, reliable, portable, and low-power solution, and a robust people's property protection solution with apparent short response time. The system contains a camera in addition to other sensors. Other aspects of this system can be improved by wirelessly connecting the system components, thereby increasing the ultrasound sensor range and applying a technique to determine the speed of approaching obstacles. While developing such a solution was beneficial to people or businessmen. The device designed in this business is only capable of detecting the image of the thief and sending it via e-mail. In the future, adjustments will be added to improve system performance. These include: A global positioning method for finding the location of a bag using GSM and GPS units to connect the location to a nearby location.

\section{ACKNOWLEDGMENT}

The authors would like to thank AL_Mustansiriyah University (www.uomusiriyah.edu.iq), Baghdad-Iraq for its support in the present work.

\section{REFERENCES}

[1] Raspberry pi education manual, Version 1.0 December 2012

[2] Pritish Sachdeva and Shrutik Katchii,“A Review Paper on Raspberry Pi”,Vol.4, No.6,Dec 2014

[3] Dhaval Chheda, Divyesh Darde \& Shraddha Chitalia, Smart Projectors using Remote Controlled Raspberry

Pi,International Journal of Computer Applications (0975 - 8887),Volume 82 - No. 16,2013, pp.6-1

[4] Gurjashan Singh Pannu, Mohammad Dawud \& Pritha Gupta "Design and Implementation of Autonomous Car using Raspberry Pi” International Journal of Computer Applications (0975 - 8887) Volume 113 - No. 9, March 2015.

[5] M. Schmidt, Raspberry Pi - A Quick Start Guide, The Pragmatic Bookshelf, 2013

[6] M. Richardson and S. Wallace, Getting started with Raspberry Pi, O’Reilly, USA, 2013

[7] Raspberry Pi Getting Started Guide, RS Components, Vsn 1.0, 2012.

[8] Mirjana Maksimović, Vladimir Vujović, Nikola Davidović, Vladimir Milošević and Branko Perišić "Raspberry Pi as Internet of Things hardware: Performances and Constraints", Branko Perisic on 13 February 2015.

[9] D. Uckelmann, M. Harrison, F. Michahelles, Architecting the Internet of Things, Springer 2011.

[10] Beagle Board, Available: http://beagleboard.org/Products/BeagleBone\%20Black, 21.1.2014.

[11] Phidgets, Available: http://www.phidgets.com/, [21.1.2014]

[12] UDOO Starting manual (beta) v04, (2013), Available: www.udoo.org, [21.1.2014]

[13] B. Horan, Practical Raspberry Pi, Apres, USA, 2013

[14] Sayali H. Suryavanshi1, Shreya R. Vaingankar2, Smit S. Patil3, Prof. Sayali Kor“Automobile Accident Prevention Using Ultrasonic", International Journal of Advanced Research in

Computer Science and Software EngineeringVolume 5, Issue 3, 2015.

[15] Ayad Ahmed Ebrahim, Ruzairi Abdul Rahim, Anita Ahmad, Khairul Hamimah Abas , ULTRASONIC SENSOR FOR DISTANCE MEASUREMENT “,Process Tomography \& Instrumentation System, March 2016.

[16] components101 Available: https://components101.com/ultrasonic-sensor-working-pinout-datasheet, 18 September 2017 